\title{
The Dilemma of Choosing Talent: \\ Michael Jordans are Hard to Find
}

\author{
by \\ Peter A. Groothuis \\ Associate Professor \\ 3093 Raley Hall \\ Appalachian State University \\ Boone, NC 28608 \\ (828) 262-6077
J. Richard Hill
Professor \\ 317 Sloan Hall \\ Central Michigan University \\ Mt. Pleasant, MI 48859 \\ (989) 774-3706 \\ hill1jr@cmich.edu \\ and \\ Timothy Perri \\ Professor \\ 3092 Raley Hall \\ Appalachian State University \\ Boone, NC 28608 \\ (828) 262-2251
}

Spring 2007

Abstract: This paper explores the dilemma of choosing talent using NBA data from 1987-2003. We find that there is much uncertainty in selecting talent. If superstars are found they are usually identified early, however, more false positive exist than correct decisions with high draft picks. Our results suggest that the dilemma of choosing talent is not so much a winner's curse but more like a purchase of a lottery ticket. Most times you lose but if you are going to win you must buy one. 


\section{Introduction}

Economics has a long history of situations where agents have expost regrets from decisions made under uncertainty. In the now classic case of the winner's curse agents who have differing beliefs about an amenity value will find that in an auction the winner of the auction will be the bidder that overvalued that amenity. Capen, Clap and Cambell (1971) provide one of the first references to the winners curse looking at competitive bidding for oil leases, while Cassing and Douglas (1980) provides an example of the winner's curse in baseball free agency. More recently Lazear (2004) identifies the Peter Principle as a situation where individuals who are promoted may have been lucky in a stochastic sense and be promoted above their performance level.

Nowhere is the problem more pronounced than in the pursuit of talent. Sports teams are in pursuit of the next Michael Jordan, movie studios in pursuit of the next Titanic, and music producers the next Beatles. Yet player after player, movie after movie, and singer after singer fall short and fail to meet expectations. In the pursuit of superstars there are many false positives. We identify this problem as the dilemma of choosing talent. In section one; we model the dilemma of choosing talent when the distribution of talent is known to be from the upper portion of a talent distribution. In section two we test the theory using a panel study of players in the NBA from 1987-2003. We conclude with a discussion of the dilemma of choosing talent and how it relates to the economics of superstars.

\section{Section 1: The Model}

To formally model the problem of choosing talent consider what happens to the probability of finding high quality talent when the lower bound for high quality increases. Assume 
$\bullet \mathrm{x}=$ talent, $\mathrm{x}_{\mathrm{L}} \leq \mathrm{x} \leq \mathrm{x}_{\mathrm{H}}$

- $\mathrm{x} \sim$ continuously with a p.d.f of $\mathrm{f}(\mathrm{x})$ \& a c.d.f of $\mathrm{F}(\mathrm{x})$

- $\mathrm{x}^{*}$ is the minimum level for high quality talent

- A potential employer observes a binary signal which is either favorable or unfavorable

- $\mathrm{P}=\operatorname{prob}(\mathrm{x}>\mathrm{x} \mid$ favorable $)$

Thus, from Bayes theorem we have:

$$
\mathrm{P}=\frac{\operatorname{prob}\left(\text { favorable } \mid \mathrm{x}>\mathrm{x}^{*}\right) \operatorname{prob}\left(\mathrm{x}>\mathrm{x}^{*}\right)}{\operatorname{prob}\left(\text { favorable } \mid \mathrm{x}>\mathrm{x}^{*}\right) \operatorname{prob}\left(\mathrm{x}>\mathrm{x}^{*}\right)+\operatorname{prob}\left(\text { favorable } \mid \mathrm{x}<\mathrm{x}^{*}\right) \operatorname{prob}\left(\mathrm{x}<\mathrm{x}^{*}\right)} .
$$

$\operatorname{Note} \operatorname{prob}\left(x>x^{*}\right)=1-F\left(x^{*}\right)$ and $\operatorname{prob}\left(x^{2}<x^{*}\right)=F\left(x^{*}\right)$.

Now suppose the probability of a favorable signals increases linearly in x: $\operatorname{prob}($ favorable $\mid \mathrm{x})=\mathrm{x} / \mathrm{x}_{\mathrm{H}}$. This means those with $\mathrm{x}=\mathrm{x}_{\mathrm{H}}$ have a probability of one of receiving a favorable signal; others have a smaller probability of a favorable signal.

Now prob(favorable $\left.\mid \mathrm{x}>\mathrm{x}^{*}\right)=\int_{x_{*}}^{\mathrm{x}_{\mathrm{H}}} \frac{\mathrm{x}}{\mathrm{x}_{\mathrm{H}}} \mathrm{f}(\mathrm{x}) \mathrm{dx} /\left[1-\mathrm{F}\left(\mathrm{x}^{*}\right)\right]$, and prob(favorable $\left.\mid \mathrm{x}<\mathrm{x}^{*}\right)=$ $\int_{x_{L}}^{x^{*}} \frac{x}{x_{H}} f(x) d x / F\left(x^{*}\right)$. We then can simplify eq.(1):

$$
P=\int_{x^{*}}^{x_{H}} x f(x) d x / \int_{x_{L}}^{x_{H}} x f(x) d x .
$$

The denominator of ( $\left.1^{\prime}\right)$ is the population mean of $\mathrm{x}, \overline{\mathrm{X}}$.Clearly $\partial \mathrm{P} / \partial \mathrm{x}^{*}$ is negative: the higher the level of talent desired $\left(\mathrm{dx}^{*}>0\right)$, the smaller the probability someone with a favorable signal exceeds the cut off for high talent $\left(\mathrm{x}^{*}\right)$. Also $\partial \mathrm{P} / \partial \overline{\mathrm{X}}$ is 
negative: the more talented the population, on average, the smaller the probability someone with a favorable signal exceeds the cut off for high talent.

Note: these results do not depend on a "thin tail" at the upper end of the ability distribution; all we have specified is the distribution is continuous. For further insight, suppose $\mathrm{x} \sim$ uniformly on

$[\overline{\mathrm{X}}-\Delta, \overline{\mathrm{X}}+\Delta]$. We have:

$$
\mathrm{P}=\frac{\left(\mathrm{X}_{\mathrm{H}}\right)^{2}-(\mathrm{x} *)^{2}}{4 \Delta \overline{\mathrm{X}}}
$$

Now $\partial \mathrm{P} / \partial \Delta<0$, so a larger variance of $\mathrm{x}$ (which is positively related to $\Delta$ ) implies a smaller probability someone with a favorable signal exceeds the cut off for high talent. Suppose $\bar{X}=6 \& \Delta=5$. A firm that desired an above-average worker $\left(\mathrm{x}^{*}=6\right)$ would, choosing at random, obtain such a worker with a 50\% probability. Using (1”), the signal would correctly identify such an individual $71 \%$ of the time. If the firm desired someone with $x>10$, choosing at random, it would obtain such an individual $10 \%$ of the time. Using the signal, it would obtain such an individual $17.5 \%$ of the time.

\section{Section 2: Empirical Results}

To empirically test the model of the dilemma of choosing talent we focus on NBA data of performance from the 1987-88 season to the 2003-04 season. We use a measure of player performance called the efficiency formula to develop a distribution of talent. As reported by NBA.com, this index is calculated per game as: (points + rebounds + assists + steals + blocks $)$ - ((field goals attempted - field goals made) + (free throws attempted free throws made) + turnovers)). This measure provides a measure of quality that is based upon performance in all aspects of the games. In table 1, we report the mean, 
median, standard deviation and highest level of the efficiency rating. We find that in all cases the mean is higher than the median suggesting a skewed right distribution of talent. We also find that the highest value is always over three standard deviations from the mean. In figure one we plot a distribution of efficiency ratios for the 2001-02 season. The distribution is skewed right with only a few players in the top tail of the distribution. In table 2, we focus on the players whose efficiency rating is two standard deviations from the mean. We find that from 12 to 22 players a year have efficiency ratings over two standard deviations from the mean in any given year. During this time period, we find that only two players who were in this elite category were undrafted, Ben Wallace in 2001-02 season and Brad Miller in the 2003-04 season. Many were on the list a multiple of times, some as many as 9 years. During this time, we find that many of the number one picks and lottery picks are in the elite category. Some number one picks, however, never show up on the list. Still others only make the list one time in their career.

In table 3, we look at only the top 5 players in efficiency ratings. We find that in our 17 year panel only 19 players fill the 85 spots in this time period. Most were on the list a multiple of times. The lowest rank in the draft on this list was the $13^{\text {th }}$ pick- two players, Karl Malone in 1985 and Kobe Bryant in 1996. Many of the top players were number one draft picks. Many number one picks, however, did not make the top 5 players in the NBA. In fact many of the top picks did not make it to two deviations above the mean. There are many false positives.

In Table 4 the mean, standard deviation, minimum value, maximum value and number of observations for efficiency are reported by draft number. The figures in this table reveal some interesting results. First the drop off in efficiency between the first 
pick in the draft and the second pick is statistically significant. ${ }^{1}$ The decrease in mean efficiency is also statistically significant between the fifth and sixth picks. There is a general negative relationship between mean efficiency and draft number; exceptions to this trend occur when lower picked players overachieve (e.g. Both Karl Malone and Kobe Bryant were thirteenth picks in the draft). Overall the draft appears to represent either an efficient judge of talent or a self-fulfilling prophesy (teams may give number one picks more minutes and more opportunities to be a superstar).

In table 5, we summarize the dilemma of choosing talent by calculating the percentage of players who obtain superstar status by draft number. Column one calculates the percentage of players who have at least one season of performance two standard deviations above the mean. We find that 80 percent of number one draft picks have at least one superstar season where their performance is two standard deviations above the mean. This percentage falls of quickly with number two draft picks with only forty percent and number 3 draft picks having thirty percent. Column two reports the percentage of players by draft pick who make the top five players in the league. Here we find that the dilemma of choosing talent is great where only 35 percent of number one draft picks perform at this level and this falls of even more quickly. Finding superstars is a rare event indeed.

To further test the dilemma of choosing talent, we use a random effects panel model to estimate player's efficiency ratings. A simple equation to represent the model is:

$$
E f f_{i t}=\alpha+\beta_{1} X_{1 i t}+\beta_{2} X_{2 i t-1}+\varepsilon_{i t}
$$

where $i$ refers to the individual player, $E f f_{\text {ii }}$ represents the efficiency of the player in year t, $X_{1}$ is a vector of time-invariant player characteristics, $X_{2(t-1)}$ is a vector of experience measures and $\varepsilon_{t}$ is vector of disturbances. The only time variant player characteristics

\footnotetext{
${ }^{1}$ The value of the test statistic is 6.5239 . This is greater than the critical value at the .005 level of significance given the degrees of freedom.
} 
included in the model are experience and experience squared; no performance statistics are used since efficiency is computed from these stats. Time invariant personal characteristics used to explain efficiency are player height, weight, years of college and a dummy variable equal to one for white players.

Two options for estimating this model are the fixed effects approach and the random effects approach. In the fixed effects formulation of the model differences across individuals are captured in differences in the constant term; thus any time-invariant personal characteristics are dropped from the regression. In this formulation of the model it is impossible to determine if differences exist between players in terms of efficiency due to draft number or other time-invariant variables. Therefore the fixed effects model will not be used.

In the random effects formulation the differences between individuals is modeled as parametric shifts of the regression function. This technique of estimating panel data allows for estimates of all of the time-invariant personal characteristics as well as the experience statistics. Breusch and Pagan (1980) developed a Lagrange multiplier test (LM Test) for the appropriateness of the random effects model compared to the OLS format. $^{2}$ The Lagrange Multiplier test statistic is 9481.09, which greatly exceeds the 95 percent chi-squared with one degree of freedom, 3.84. Thus the simply OLS regression model with a single constant term is inappropriate.

In table 6 we report these results. In regression I, draft number, experience, experience squared, years of college and race are all statistically significant determinants of efficiency; height and weight are not. As expected, efficiency declines as draft number rises. Efficiency initially rises with experience then declines. Efficiency declines as years of college rises; this reflects the early entry of outstanding college or high school players.

\footnotetext{
${ }^{2}$ See Stata Release 6 , Reference SU-Z pp. 438-439 for details or Greene (2000) , pp. 572-573.
} 
The negative coefficient for white players is interesting. A priori we would expect this coefficient to equal zero. The results suggest that white players may be drafted higher than the future performance would indicate. Regression II is run minus the white variable. There is no change in sign or significance of the remaining variables.

The R-square of the models is around $16 \%-17 \%$ overall. It is somewhat higher in explaining variation in efficiency between players, approximately $22 \%$, and between years for the same players, 23\%. In general the results suggest a great deal of unexplained variation in player efficiency from season to season.

\section{Conclusions}

The dilemma of choosing talent suggests that when talent is thin more false positive signals exist than correct decisions. Using NBA data we find that there is much uncertainty in selecting talent. Our results also show that if superstars are found they are usually identified early, however, more false positive exist than correct decisions with high draft picks. Our results suggest that the dilemma of choosing talent is not so much a winner's curse but more like a purchase of a lottery ticket. Most times you lose but if you are going to win you must buy one. 
Table 1: NBA Efficiency: Means, Medians, and Standard Deviations: 1987-2003

\begin{tabular}{|c|c|c|c|c|}
\hline Season & Mean & Median & $\begin{array}{l}\text { Standard } \\
\text { Deviation }\end{array}$ & Highest \\
\hline 1987-1988 & 11.79 & 10.45 & 6.82 & 35.04 \\
\hline 1988-1989 & 10.05 & 8.68 & 7.19 & 36.9 \\
\hline 1989-1990 & 9.96 & 8.02 & 7.23 & 34.6 \\
\hline 1990-1991 & 10.32 & 9.06 & 6.89 & 33.5 \\
\hline 1991-1992 & 9.91 & 8.38 & 6.98 & 32.6 \\
\hline 1992-1993 & 9.94 & 8.49 & 6.66 & 34.4 \\
\hline 1993-1994 & 9.43 & 8.35 & 6.49 & 34.0 \\
\hline 1994-1995 & 9.50 & 8.14 & 6.41 & 32.4 \\
\hline 1995-1996 & 9.33 & 8.00 & 6.43 & 32.0 \\
\hline 1996-1997 & 8.93 & 7.21 & 6.42 & 30.2 \\
\hline 1997-1998 & 8.81 & 7.59 & 6.14 & 29.2 \\
\hline 1998-1999 & 8.05 & 7.12 & 5.94 & 28.8 \\
\hline 1999-2000 & 8.94 & 7.93 & 6.03 & 33.8 \\
\hline 2000-2001 & 8.88 & 7.29 & 6.20 & 31.0 \\
\hline 2001-2002 & 8.98 & 7.88 & 6.09 & 31.2 \\
\hline 2002-2003 & 8.78 & 7.46 & 6.19 & 32.1 \\
\hline 2003-2004 & 8.60 & 7.22 & 5.97 & 33.1 \\
\hline
\end{tabular}


Table 2: Superstar Seasons Based on Efficiency Ratings

\begin{tabular}{|c|c|}
\hline Season & $\begin{array}{l}\text { Draft Year and Draft Number of Players whose performance was two } \\
\text { Standard deviations above the mean based on efficiency measure }\end{array}$ \\
\hline 1987-1988 & $84-3,78-6,84-5,84-1,83-14,79-1,85-13,84-16,80-3,82-11$ \\
\hline 1988-1989 & $84-3,79-1,84-5,84-1,85-13,83-14,82-11,85-1,84-16,87-7,78-6,85-7$ \\
\hline 1989-1990 & $84-3,84-1,85-1,85-13,84-5,87-1,79-1,78-6,84-16,87-7,85-7,83-14,82-11,81-8$ \\
\hline 1990-1991 & $\begin{array}{l}\text { 87-1, 84-3, 85-13, 84-5, 84-1, 85-1, 79-1, 86-7, 84-16, 87-7, 82-3, 85-7, 85-66, 86-1, } \\
89-14,78-6,81-20,83-14\end{array}$ \\
\hline 1991-1992 & $\begin{array}{l}\text { 87-1, 84-3, 85-13, 84-1, 85-1, 84-5, 86-1, 86-27, 89-1, 84-11, 83-14, } \\
78-6,87-5,84-16,85-7,91-1,82-3,81-20,89-14\end{array}$ \\
\hline 1992-1993 & $\begin{array}{l}\text { 84-1, 84-5, 84-3, 85-13, 87-1, 92-1, 86-1, 85-1, 91-1, 82-3, 90-1, 85-8, 92-2, 81-20, 89- } \\
14,91-4\end{array}$ \\
\hline 1993-1994 & $87-1,92-1,84-1,85-13,85-1,84-5,87-5,89-17,90-1,84-16,92-2,84-11,87-10,93-1$ \\
\hline 1994-1995 & $\begin{array}{l}\text { 87-1, 84-1, 92-1, 85-13, 84-5, 85-1, 87-5, 89-26, 84-16, 92-2, 84-3, } \\
89-17,93-1,83-14,90-1,91-4,89-16,93-3\end{array}$ \\
\hline 1995-1996 & $\begin{array}{l}\text { 87-1, 84-1, 84-3, 85-13, 84-5, 92-1, 92-2, 94-3, 93-1, 89-17, 93-3, 85-1, 87-1, 91-1, 83- } \\
14,84-16\end{array}$ \\
\hline 1996-1997 & $\begin{array}{l}\text { 85-13, 92-1, 84-5, 84-3, 94-3, 93-1, 88-53, 84-1, 85-1, 87-7, 93-8, 90-2, 87-5, 92-2, 92- } \\
24,84-16,92-6,91-4\end{array}$ \\
\hline 1997-1998 & $\begin{array}{l}\text { 85-13, 92-1, 97-1, 87-1, 95-5, 93-1, 84-3, 92-6, 94-3, 84-1, 84-5, 85-1, 90-2, 88-19, 91- } \\
\text { 4, 86-24, 92-2 }\end{array}$ \\
\hline 1998-1999 & $\begin{array}{l}\text { 92-1, 85-13, 93-1, 97-1, 94-2, 92-2, 95-5, 84-5, 95-2, 84-1, 90-2, 94-3, 89-17, 87-1, 96- } \\
\text { 3, 92-6, 89-26, 91-4 }\end{array}$ \\
\hline 1999-2000 & $\begin{array}{l}\text { 92-1, 95-5, 93-1, 97-1, 85-13, 90-2, 92-2, 94-3, 91-4, 98-5, 96-3, 96-13, 87-1, 94-2, 95- } \\
21,99-1\end{array}$ \\
\hline $2000-2001$ & $\begin{array}{l}\text { 92-1, 93-1, 95-5, 97-1, 96-13, 97-9, 85-13, 95-2, 98-9, 98-5, 99-9, 90-2, 96-6, 99-1, 96- } \\
\text { 3, 94-2, 96-1, 96-5, 95-4, 98-10, 82-18, 99-2 }\end{array}$ \\
\hline 2001-2002 & $\begin{array}{l}\text { 97-1, 92-1, 95-5, 93-1, 98-9, 97-9, 99-1, 90-2, 98-10, 96-13, 85-13, 99-8, 99-9, 96-3, } \\
\text { 96-Undrafted, 96-17, 94-2, 96-1, 96-6 }\end{array}$ \\
\hline 2002-2003 & $\begin{array}{l}\text { 95-5, 97-1, 92-1, 97-9, 96-13, 98-9, 93-1, 99-1, 99-9, 96-17, 98-10, 96-9, 94-2, 85-13, } \\
01-3,96-3,99-2,90-2\end{array}$ \\
\hline 2003-2004 & $\begin{array}{l}\text { 95-5, 97-1, 99-1, 92-1, 98-9, 97-9, 96-14, 99-undrafted, 96-13, 99-9, } \\
02-35,99-24,96-17,01-19,96-5,93-24,02-1\end{array}$ \\
\hline
\end{tabular}


Table 3: Top Five Players Based on Efficiency Ratings: 1987-2003 Seasons

\begin{tabular}{|c|c|}
\hline Season & Player Name, Draft Year, and Draft Number \\
\hline 1987-1988 & $\begin{array}{l}\text { Michael Jordan: 84-3, Larry Bird: 78-6, Charles Barkley: 84-5, } \\
\text { Hakeem Olajuwon: 84-1, Clyde Drexler: 83-14 }\end{array}$ \\
\hline 1988-1989 & $\begin{array}{l}\text { Michael Jordan: 84-3, Magic Johnson: 79-1, Charles Barkley: 84-5, } \\
\text { Hakeem Olajuwon: 84-1, Karl Malone: 85-13 }\end{array}$ \\
\hline 1989-1990 & $\begin{array}{l}\text { Michael Jordan: 84-3, Hakeem Olajuwon:84-1, Patrick Ewing: 85-1, } \\
\text { Karl Malone: 85-13, Charles Barkley: 84-5 }\end{array}$ \\
\hline 1990-1991 & $\begin{array}{l}\text { David Robinson: 87-1, Michael Jordan: 84-3, Karl Malone: 85-13, } \\
\text { Charles Barkley: 84-5, Hakeem Olajuwon: 84-1 }\end{array}$ \\
\hline 1991-1992 & $\begin{array}{l}\text { David Robinson:87-1, Michael Jordan: 84-3, Karl Malone: 85-13, } \\
\text { Hakeem Olajuwon: 84-1, Patrick Ewing: 85-1 }\end{array}$ \\
\hline 1992-1993 & $\begin{array}{l}\text { Hakeem Olajuwon 84-1, Charles Barkley: 84-5, Michael Jordan: 84-3, } \\
\text { Karl Malone: 85-13, David Robinson: 87-1 }\end{array}$ \\
\hline 1993-1994 & $\begin{array}{l}\text { David Robinson: 87-1, Shaquille O’Neal: 92-1, Hakeem Olajuwon: 84- } \\
\text { 1, Karl Malone: 85-13, Patrick Ewing: 85-1 }\end{array}$ \\
\hline 1994-1995 & $\begin{array}{l}\text { David Robinson:87-1, Hakeem Olajuwon: 84-1, Shaquille O’Neal: 92- } \\
\text { 1, Karl Malone: 85-13, Charles Barkley: 84-5 }\end{array}$ \\
\hline 1995-1996 & $\begin{array}{l}\text { David Robinson: 87-1, Hakeem Olajuwon: 84-1, Michael Jordan 84-3, } \\
\text { Karl Malone: 85-13, Charles Barkley: 84-5 }\end{array}$ \\
\hline 1996-1997 & $\begin{array}{l}\text { Karl Malone: 85-13, Shaquille O’Neal: 92-1, Charles Barkley: 84-5, } \\
\text { Michael Jordan: 84-3, Grant Hill: 94-3 }\end{array}$ \\
\hline 1997-1998 & $\begin{array}{l}\text { Karl Malone: 85-13, Shaquille O’Neal: 92-1, Tim Duncan: 97-1, } \\
\text { David Robinson: 87-1, Kevin Garnett: 95-5 }\end{array}$ \\
\hline 1998-1999 & $\begin{array}{l}\text { Shaquille O’Neal: 92-1, Karl Malone: 85-13, Chris Webber: 93-1, } \\
\text { Tim Duncan: 97-1, Jason Kidd: 94-2 }\end{array}$ \\
\hline $1999-2000$ & $\begin{array}{l}\text { Shaquille O’Neal: 92-1, Kevin Garnett: 95-5, Chris Webber: 93-1, } \\
\text { Tim Duncan: 97-1, Karl Malone: 85-13 }\end{array}$ \\
\hline $2000-2001$ & $\begin{array}{l}\text { Shaquille O’Neal: 92-1, Chris Webber: 93-1, Kevin Garnett: 95-5, } \\
\text { Tim Duncan: 97-1, Kobe Bryant: 96-13 }\end{array}$ \\
\hline 2001-2002 & $\begin{array}{l}\text { Tim Duncan: 97-1, Shaquille O’Neal: 92-1, Kevin Garnett: 95-5, } \\
\text { Chris Webber: 93-1, Dirk Nowitzski: 98-9 }\end{array}$ \\
\hline 2002-2003 & $\begin{array}{l}\text { Kevin Garnett: 95-5, Tim Duncan: 97-1, Shaquille O’Neal: 92-1, } \\
\text { Tacy McGrady: 97-9, Kobe Bryant: 96-13 }\end{array}$ \\
\hline 2003-2004 & $\begin{array}{l}\text { Kevin Garnett: 95-5, Tim Duncan: 97-1, Elton Brand: 99-1, } \\
\text { Shaquille O’Neal: 92-1, Dirk Nowitzski: 98-9 }\end{array}$ \\
\hline
\end{tabular}


Figure 1

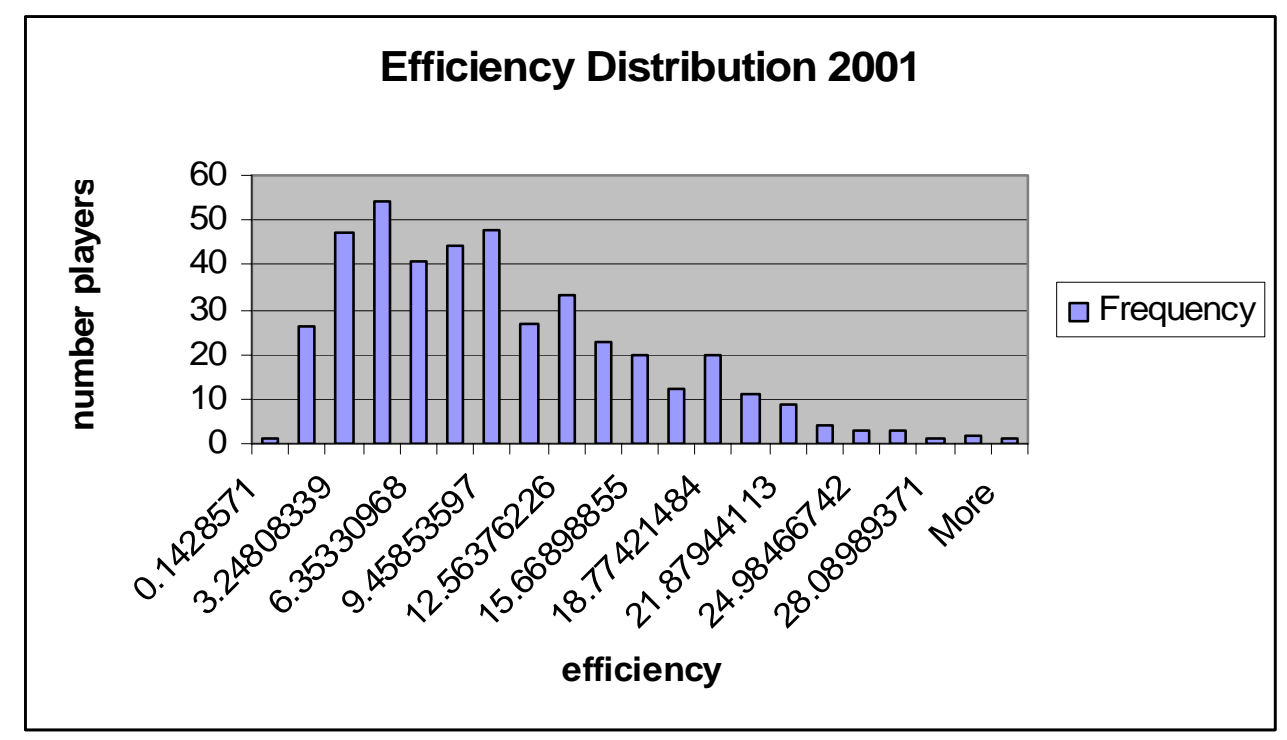


Table 4:Mean and Standard Deviation by Draft Number: (1987-2003)

\begin{tabular}{|c|c|c|c|c|c|}
\hline Draft Number & Mean & Std. Dev. & Min & Max & Obs.(N/n) \\
\hline 1 & 19.47 & 7.84 & 1.67 & 34.41 & $213 / 26$ \\
\hline 2 & 15.07 & 5.55 & 1.89 & 26.33 & $184 / 22$ \\
\hline 3 & 15.75 & 6.68 & .67 & 36.99 & $188 / 24$ \\
\hline 4 & 13.79 & 5.17 & 1.95 & 23.80 & $182 / 20$ \\
\hline 5 & 14.44 & 7.14 & 1.08 & 33.13 & $199 / 24$ \\
\hline 6 & 10.92 & 6.26 & .75 & 34.01 & $157 / 23$ \\
\hline 7 & 12.59 & 6.00 & 1.09 & 29.2 & $177 / 25$ \\
\hline 8 & 11.83 & 5.89 & -.52 & 26.1 & $177 / 24$ \\
\hline 9 & 12.30 & 6.54 & .14 & 28.8 & $193 / 23$ \\
\hline 10 & 12.11 & 5.45 & 2.36 & 27 & $156 / 21$ \\
\hline 11 & 11.47 & 5.68 & 1.19 & 27.48 & $191 / 22$ \\
\hline 12 & 9.36 & 5.06 & 1.33 & 23.44 & $148 / 23$ \\
\hline 13 & 12.11 & 7.59 & -.67 & 31.88 & $167 / 21$ \\
\hline 14 & 10.58 & 6.90 & -1 & 28.87 & $142 / 22$ \\
\hline 15 & 8.86 & 4.60 & -.4 & 20.06 & $119 / 18$ \\
\hline 16 & 9.54 & 6.21 & -.25 & 27.40 & $146 / 22$ \\
\hline 17 & 9.46 & 6.05 & .67 & 24.73 & $112 / 19$ \\
\hline 18 & 10.07 & 5.22 & .43 & 21.67 & $139 / 21$ \\
\hline 19 & 8.70 & 5.83 & -.33 & 22.05 & $116 / 20$ \\
\hline 20 & 9.17 & 5.55 & 0 & 24.51 & $117 / 23$ \\
\hline 21 & 8.14 & 5.19 & .33 & 22.08 & $127 / 19$ \\
\hline 22 & 7.94 & 5.38 & .33 & 19.89 & $99 / 21$ \\
\hline 23 & 8.86 & 4.80 & .2 & 21.7 & $118 / 20$ \\
\hline 24 & 10.26 & 6.02 & -2 & 22.87 & $128 / 19$ \\
\hline 25 & 7.18 & 5.53 & -1 & 23.06 & 79/18 \\
\hline 26 & 7.83 & 6.27 & .2 & 24.45 & $76 / 16$ \\
\hline
\end{tabular}


Table 5: Percentage of Players who become superstars by draft pick number

\begin{tabular}{|c|c|c|}
\hline Draft Pick & $\begin{array}{l}\text { Percentage with at Least One } \\
\text { Superstar Season }\end{array}$ & $\begin{array}{l}\text { Percentage with at least one TOP } \\
\text { FIVE Season }\end{array}$ \\
\hline 1 & $80 \%$ & $35 \%$ \\
\hline 2 & $40 \%$ & $5 \%$ \\
\hline 3 & $30 \%$ & $10 \%$ \\
\hline 4 & $10 \%$ & $0 \%$ \\
\hline 5 & $30 \%$ & $2 \%$ \\
\hline $6-10$ & $12 \%$ & $2 \%$ \\
\hline $11-15$ & $5 \%$ & $2 \%$ \\
\hline $16-20$ & $6 \%$ & $0 \%$ \\
\hline $21-25$ & $5 \%$ & $0 \%$ \\
\hline $26-29$ & $4 \%$ & $0 \%$ \\
\hline
\end{tabular}


Table 6: Random Effects GLS Efficiency Regression Results: (1987-2003)

\begin{tabular}{|c|c|c|}
\hline Variable & I & II \\
\hline Constant & $\begin{array}{l}13.399 \\
(4.046)\end{array}$ & $\begin{array}{l}16.290 \\
(4.973)\end{array}$ \\
\hline Draft Number & $\begin{array}{c}-.105 \\
(-21.393)\end{array}$ & $\begin{array}{c}-.108 \\
(-22.078)\end{array}$ \\
\hline Height & $\begin{array}{c}-.028 \\
(-0.506)\end{array}$ & $\begin{array}{c}-.071 \\
(-1.29)\end{array}$ \\
\hline Weight & $\begin{array}{c}.007 \\
(0.987)\end{array}$ & $\begin{array}{c}.007 \\
(1.042)\end{array}$ \\
\hline Experience & $\begin{array}{c}.956 \\
(24.655)\end{array}$ & $\begin{array}{c}.952 \\
(24.533)\end{array}$ \\
\hline Experience Squared & $\begin{array}{c}-.102 \\
(-33.605)\end{array}$ & $\begin{array}{c}-.101 \\
(-33.530)\end{array}$ \\
\hline Years of College & $\begin{array}{c}-.539 \\
(-5.066)\end{array}$ & $\begin{array}{c}-.489 \\
(-4.586)\end{array}$ \\
\hline White & $\begin{array}{c}-1.321 \\
(-4.709)\end{array}$ & \\
\hline $\begin{array}{c}\text { R-Sq: Within } \\
\text { Between } \\
\text { Overall }\end{array}$ & $\begin{array}{l}.2327 \\
.2268 \\
.1745\end{array}$ & $\begin{array}{l}.2331 \\
.2184 \\
.1637\end{array}$ \\
\hline
\end{tabular}

Z-statistics are in parentheses below the coefficients. 


\section{Bibliography}

Breusch; T. S, and A. R. Pagan, “The Lagrange Multiplier Test and its Applications to Model Specification in Econometrics,'The Review of Economic Studies, Vol. 47, No. 1, Econometrics Issue. (Jan., 1980), pp. 239-253.

Capen, E.C., R.V. Clapp and W.M. Campbell "Competitive Bidding in High-Risk Situations,' Journal of Petroleum Technology, June 1971, pp.641-653.

Cassing, James and Richard Douglas "Implications of the Auction Mechanism in Baseball Free Agent Draft” Southern Economics Journal, vol.47, July 1980, pp. 110-121.

Greene, William “Econometric Analysis,” Macmillan Publishing Company, New York, 1990.

Groothuis, Peter A., James Richard Hill, and Timothy J. Perri "Early Entry in the NBA Draft: The Influence of Unraveling, Human Capital and Option Value” Journal of Sports Economics, forthcoming.

Lazear, Edward, “The Peter Principle: A Theory of Decline” Journal of Political Economy, vol.112, no.1, 2004, pp s141-s163.

Pepall, Lynne M and Daniel J. Richards "Reach for the Stars: A Strategic Bidding Game” Economica, vol.68 2001, pp.489-504.

Rosen, Sherwin, “The Economics of Superstars” The American Economic Review, vol.71, no5, 1981, pp.845-858. 